\title{
Synthesis and Characterization of Triply Doped Nano-Composite Alumina-Phospho- Silicates $\mathrm{SiO}_{2}-\mathrm{P}_{2} \mathrm{O}_{5}-\mathrm{Al}_{2} \mathrm{O}_{3}$ with $\mathrm{Er}^{3+}, \mathrm{Sm}^{3+}$ and $\mathrm{Yb}^{3+}$ Ions Prepared by Sol Gel Technique in Two Different Forms Thin Film and Monolith
}

\author{
I. K. Battisha1, M. A. Salem', Y. Badr'2, M. Kamal ${ }^{3}$, A. M. S. El Nahrawy' \\ ${ }^{1}$ Department of Solid State Physics, National Research Center (NRC), Dokki, Egypt \\ ${ }^{2}$ National Institute of Laser Enhancement Sciences (NILES), Cairo University, Giza, Egypt \\ ${ }^{3}$ Physics Department, El Mansoura University, Mansoura, Egypt \\ Email: szbasha@yahoo.com
}

Received 17 May 2015; accepted 18 January 2016; published 21 January 2016

Copyright (C) 2016 by authors and Scientific Research Publishing Inc.

This work is licensed under the Creative Commons Attribution International License (CC BY). http://creativecommons.org/licenses/by/4.0/

(c) (i) Open Access

\section{Abstract}

Nano-composite monolith and thin film Alumina-Phospho-Silicates $\left(\mathrm{SiO}_{2}-\mathrm{P}_{2} \mathrm{O}_{5}-\mathrm{Al}_{2} \mathrm{O}_{3}\right): \mathrm{Ln}(\mathrm{Ln}=\mathrm{Sm}$, $\mathrm{Er}, \mathrm{Yb})$ glasses activated by triply doped with three different rare earth ions (REIs) $\left(\mathrm{Er}^{3+}: \mathrm{Yb}^{3+}: \mathrm{Sm}^{3+}\right)$ were prepared by modified sol-gel process. The composition of the prepared samples was as follow $\left(\mathrm{SiO}_{2}: 11 \mathrm{P}_{2} \mathrm{O}_{5}: 3 \mathrm{Al}_{2} \mathrm{O}_{3}: 1.2 \mathrm{Er}_{2} \mathrm{O}_{3}:\left(1.2\right.\right.$ - 3) $\mathrm{Yb}_{2} \mathrm{O}_{3}:\left(0.7\right.$ - 1.3) $\left.\mathrm{Sm}_{2} \mathrm{O}_{3}\right)$. Tetra-ethyl-orthosilicate (TEOS), tri-ethyl-phosphate (TEP), erbium nitrate, ytterbium nitrate and samarium nitrate were used as precursor materials, respectively. The structure of the prepared samples was studied using $\mathrm{X}$-ray diffraction (XRD), which revealed that the crystallite sizes of monolith and thin film samples both sintered at $900^{\circ} \mathrm{C}$ at constant $\mathrm{Sm}^{3+}$ concentration at $1.3 \mathrm{~mol} \%\left(\operatorname{SPAE}_{1.2} \mathrm{Y}_{1.8} \mathrm{~S}_{1.3}\right)$ have the following values 44 and $31 \mathrm{~nm}$, respectively. Transmission Electron Microscopy (TEM) of the same prepared samples was used to confirm the presence of nano-structure phase. The photo-luminescence study will be evaluated for the prepared.

\section{Keywords}

Sol Gel, XRD, TEM and Photoluminescence 


\section{Introduction}

With introduction of internet super highway and increasing demand for broadband data transmission, there is an increasing demand for performance materials with high reliability and low cost small form factor components to meet the needs of miniaturised devices. Such components (including couplers, splitters, tunable lasers, optical amplifiers, etc.) require high grade materials and industrial low cost effective processes. Indeed, sol-gel process appeared to us as one of the best processes to consider. Interaction between $\mathrm{SiO}_{2}$ and $\mathrm{P}_{2} \mathrm{O}_{5}$ derivatives could serve as a model for the precursor coating in the integrated optics technology. Silicon oxide resulting from Si device could serve as interface for a better adherence of the film.

Incorporating rare earth ions in the host matrix also allow controlling its refractive index as well as its optical activity, absorption etc. However, a limitation for such optical devices is the precipitation of rare earth oxides or insoluble phospho-silicates. Therefore, it is worth to investigate the sol-gel preparation process of the prepared samples that determine the highest concentration of rare earth allowed without running into uncontrolled crystallization and clustering problems. It is also of importance to underline the chemical durability of the materials as most of $\mathrm{P}_{2} \mathrm{O}_{5}$ based compound suffers from its hygroscopic character [1]-[5].

In the present work, a simple sol-gel procedure was successfully used for the preparation of alumina-phosphosilicate as monolith and thin film forms prepared from the same precursor materials, using the tetra-ethoxysilane and triethyl-phosphate precursors. Silica-phosphate glasses activated by $\mathrm{Sm}^{3+}, \mathrm{Er}^{3+}$ and $\mathrm{Yb}^{3+}$ ions were prepared by sol-gel route, using monolith and spin-coating methods. The structure of the prepared samples will be evaluated by using XRD. The effect of co-incorporating these two forms of materials with $\mathrm{Sm}^{3+}, \mathrm{Er}^{3+}$ and $\mathrm{Yb}^{3+}$ ions on the structure and optical properties will be discussed.

\section{Experimental}

The investigated nano-composite Alumina-Phospho-Silicates $\left(\mathrm{SiO}_{2}-\mathrm{P}_{2} \mathrm{O}_{5}-\mathrm{Al}_{2} \mathrm{O}_{3}\right)$ pure and Triply doped with three different rare earth ions (REIs) $\left(\mathrm{Er}^{3+}: \mathrm{Yb}^{3+}: \mathrm{Sm}^{3+}\right)$ have been prepared by sol-gel technique in monolith and thin film forms with sintering at different temperatures ranging from 200 up to $900^{\circ} \mathrm{C}$. The starting materials used in this study are tetraesoxisilane and triethyl phosphate for $\mathrm{SiO}_{2}$ and $\mathrm{P}_{2} \mathrm{O}_{5}$ precursors, respectively. The other trivalent oxides are incorporated using nitrate solutions as shown in the flow chart of samples preparation given in Figure 1.

As shown in Figure 1, the monolithic and thin film forms were obtained by hydrolysis and poly-condensation of tetra-ethoxysilane $\left(\mathrm{CH}_{3} \mathrm{CH}_{2} \mathrm{OH}\right)_{4} \mathrm{Si}$ (TEOS, 99.999\%, Sigma-Aldrich) and Triethyphosphate $\left(\mathrm{C}_{2} \mathrm{H}_{5} \mathrm{O}\right)_{3} \mathrm{P}(\mathrm{O})$ reacted in ethanol solution under vigorous stirring with distilled $\mathrm{H}_{2} \mathrm{O}$ containing $\mathrm{HCl}$ used as a catalyst. Then the

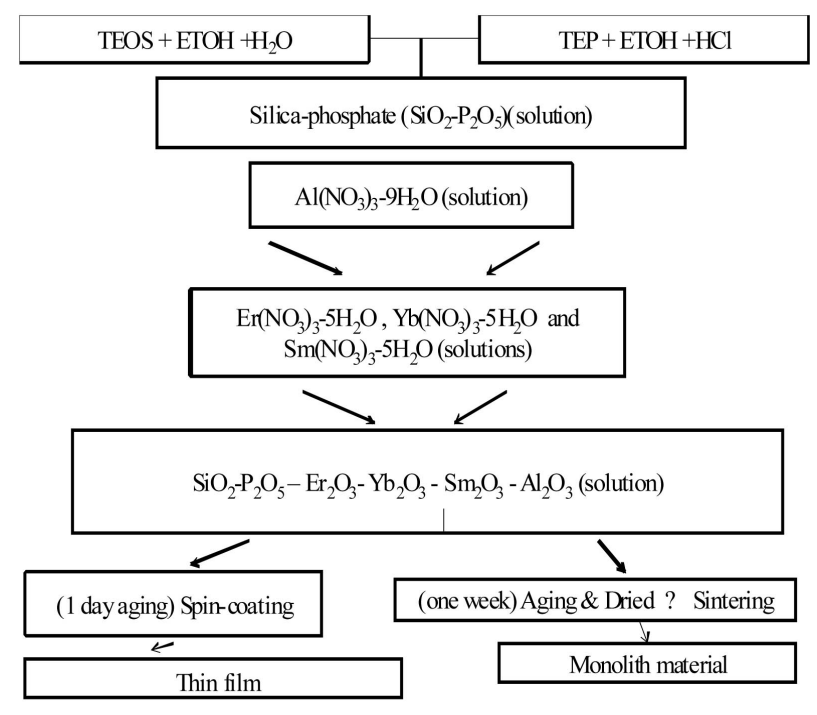

Figure 1. Flow chart for the preparation of Alumina-PhosphoSilicates gels doped with $\left(\mathrm{Er}^{3+}, \mathrm{Er}^{3+}: \mathrm{Yb}^{3+} \& \mathrm{Er}^{3+}: \mathrm{Yb}^{3+}: \mathrm{Sm}^{3+}\right)$ preparation in monolithic and thin film forms. 
$\mathrm{Er}^{3+}, \mathrm{Yb}^{3+}$ and $\mathrm{Sm}^{3+}$ ions were introduced in the process, by mixing with rare earth nitrate solutions with molar ratios of 1.2 and $1.8 \mathrm{~mol} \%$ of $\mathrm{Er}_{2} \mathrm{O}_{3}$ and $\mathrm{Yb}_{2} \mathrm{O}_{3}$ and $\mathrm{Sm}_{2} \mathrm{O}_{3}$ of 0.7, 1.1 and $1.3 \mathrm{~mol} \%$, and $3 \mathrm{~mol} \%$ of $\mathrm{Al}_{2} \mathrm{O}_{3}$, were added, respectively. In order to increase the solubility of rare earth in the glass matrix due to the valence match between the rare-earth dopant $\left(\mathrm{RE}^{3+}\right)$ and the substituted cation $\left(\mathrm{Al}^{3+}\right)$. The resulting homogeneous solutions were used to prepare both monolithic and thin film materials using the process indicated hereafter in reference [4]:

1) Preparation of monolith samples: Solutions were filled in a mold and aged for one week at room temperature and then dried in a drying oven type GFL 71.5 at about $60^{\circ} \mathrm{C}$ for about 21 days until no further shrinkage appears. Samples were found to be clear, transparent and cracks free. Densification of gel was obtained by annealing in air for three hours at temperature ranging from 60 up to $900^{\circ} \mathrm{C}$ in a muffle furnace with heating rate $1.5^{\circ} \mathrm{C} / \mathrm{min}$ as reported previously by our team work [6]-[10].

2) Thin film preparation: The remaining part of the resultant homogeneous solutions of monolith materials were used in the preparation of thin film. In this case the solutions were aged for one day at room temperature before to be dispersed on the glass and/or silica substrate, with a spun of $3500 \mathrm{rev} . / \mathrm{min}$ for 30 seconds in a clean room. At least two successive coatings were required to provide suitable effective film thickness. After finishing the coating process, the films dried for $30 \mathrm{~min}$ and then sintered at temperature ranging from $100^{\circ} \mathrm{C}$ up to $700^{\circ} \mathrm{C}$ [8].

Different typical examples of X-ray diffraction (XRD) patterns recorded for some monolith and thin film samples are given in Figures 2-5. Crystallite sizes $\mathrm{G}$ were determined using the Scherer's equation

$$
(\mathrm{G}=\mathrm{Kl} / \mathrm{D} \text { cosq })
$$

with (K) Scherer constant (0.9), $(\lambda)$ X-ray wavelength, at D (radian) = the full width at half maximum (FWHM) of the diffraction peak and $\theta=$ diffraction angle.

Microstructure and morphology for the pure Alumina-Silica-Phosphate were characterized using "JEOL transmission electron microscope” (Model: Jeol 1230 magnification up to $600 \mathrm{kx}$, resolution down to $0.2 \mathrm{~nm}$, accelerating voltage $100 \mathrm{kV}$, can reach $120 \mathrm{kV}$ through steps).

For photoluminescence (PL) measurement the samples were excited using the $514 \mathrm{~nm}$ line of a Spectra Physics 2017 Argon laser. A fiber optic probe coupled to a Dilor Super head, equipped with a suitable notch filter was employed.

The chemical composition given in Table 1 in terms of the starting mixture of the precursors used according to the chart given in Figure 1.

\section{Results and Discussion}

\section{XRD Analysis}

As expected the (as prepared) samples monolith and thin films both sintered at $900^{\circ} \mathrm{C}$ for three hours, results in a better crystallization of the analyzed XRD patterns. However even after a sintering of 3 hours at $900^{\circ} \mathrm{C}$, a slight remain of amorphous phase is still observable on XRD patterns, as shown in Figure 2. Indeed the major constituents of all prepared monolith and thin films in the present study are $\mathrm{SiO}_{2}$ and $\mathrm{P}_{2} \mathrm{O}_{5}$. Therefore it is normal to expect the resulting crystalline phases to belong to the binary system $\mathrm{SiO}_{2}-\mathrm{P}_{2} \mathrm{O}_{5}$ or close to this line. All XRD patterns in Figure 2 tend to confirm that the crystalline phases, after sintering at $900^{\circ} \mathrm{C}$ at constant $\mathrm{Er}^{3+}$ and $\mathrm{Yb}^{3+}$

Table 1. Equivalent oxide (mol \%) of the starting mixture of the investigated materials.

\begin{tabular}{|c|c|}
\hline Formal starting oxide mixture (mol \%) & Symbol \\
\hline \multicolumn{2}{|l|}{ Monolith samples } \\
\hline$\left(\mathrm{SiO}_{2}: 11 \mathrm{P}_{2} \mathrm{O}_{5}: 3 \mathrm{Al}_{2} \mathrm{O}_{3}: 1.2 \mathrm{Er}_{2} \mathrm{O}_{3}: 1.8 \mathrm{Yb}_{2} \mathrm{O}_{3}:(0.7) \mathrm{Sm}_{2} \mathrm{O}_{3}\right)$ & $\operatorname{SPAE}_{1.2} \mathrm{Y}_{1.8} \mathrm{~S}_{0.7}$ \\
\hline$\left(\mathrm{SiO}_{2}: 11 \mathrm{P}_{2} \mathrm{O}_{5}: 3 \mathrm{Al}_{2} \mathrm{O}_{3}: 1.2 \mathrm{Er}_{2} \mathrm{O}_{3}: 1.8 \mathrm{Yb}_{2} \mathrm{O}_{3}:(1.3) \mathrm{Sm}_{2} \mathrm{O}_{3}\right)$ & $\operatorname{SPAE}_{1.2} \mathrm{Y}_{1.8} \mathrm{~S}_{1.3}$ \\
\hline \multicolumn{2}{|l|}{ Thin film sample } \\
\hline$\left(\mathrm{SiO}_{2}: 11 \mathrm{P}_{2} \mathrm{O}_{5}: 3 \mathrm{Al}_{2} \mathrm{O}_{3}: 1.2 \mathrm{Er}_{2} \mathrm{O}_{3}: 1.8 \mathrm{Yb}_{2} \mathrm{O}_{3}:\left(1.3 \mathrm{Sm}_{2} \mathrm{O}_{3}\right)\right.$ & $\operatorname{SPAE}_{1.2} \mathrm{Y}_{1.8} \mathrm{~S}_{1.3}$ \\
\hline
\end{tabular}




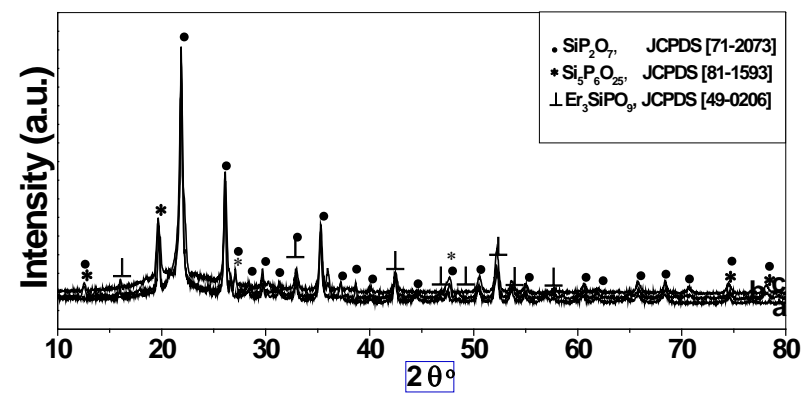

Figure 2. XRD patterns of Alumina-Phospho-Silicates monolith samples triply doped with $\mathrm{Er}^{3+}, \mathrm{Sm}^{3+}$ and $\mathrm{Yb}^{3+}$ ions; $\mathrm{SPAE}_{1.2} \mathrm{Y}_{1.8}$ with different mol\% of $\mathrm{Sm}_{2} \mathrm{O}_{3}$ equal to 0.7 (a), 1.1 (b) and 1.3 (c), as sintered for three hours at $900^{\circ} \mathrm{C}$.

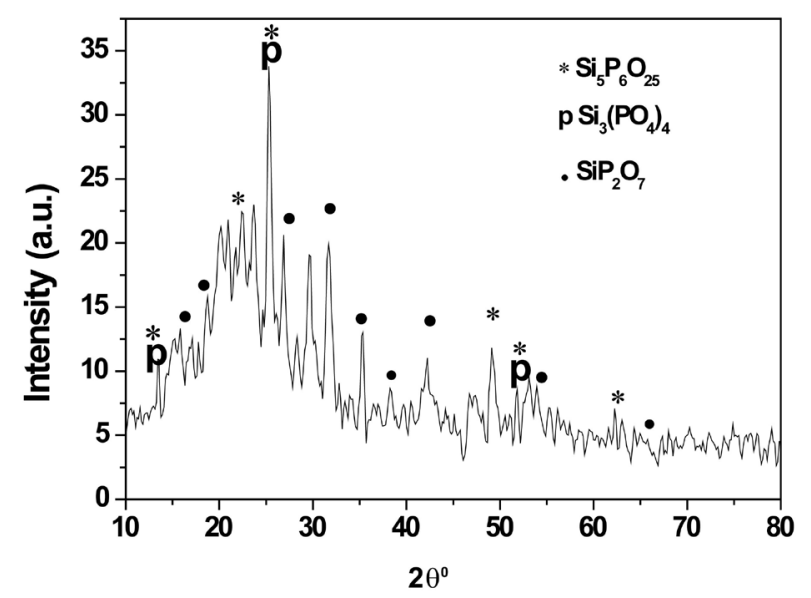

Figure 3. (a) and (b) XRD patterns of Alumina-PhosphoSilicates thin film triply doped with $\mathrm{Er}^{3+}, \mathrm{Sm}^{3+}$ and $\mathrm{Yb}^{3+}$ ions; $\mathrm{SiO}_{2}: 11 \mathrm{P}_{2} \mathrm{O}_{5}: 3 \mathrm{Al}_{2} \mathrm{O}_{3}: 1.2 \mathrm{Er}_{2} \mathrm{O}_{3}: 1.8 \mathrm{Yb}_{2} \mathrm{O}_{3}: 1.3 \mathrm{Sm}_{2} \mathrm{O}_{3}$, as sintered for three hours at $900^{\circ} \mathrm{C}$.
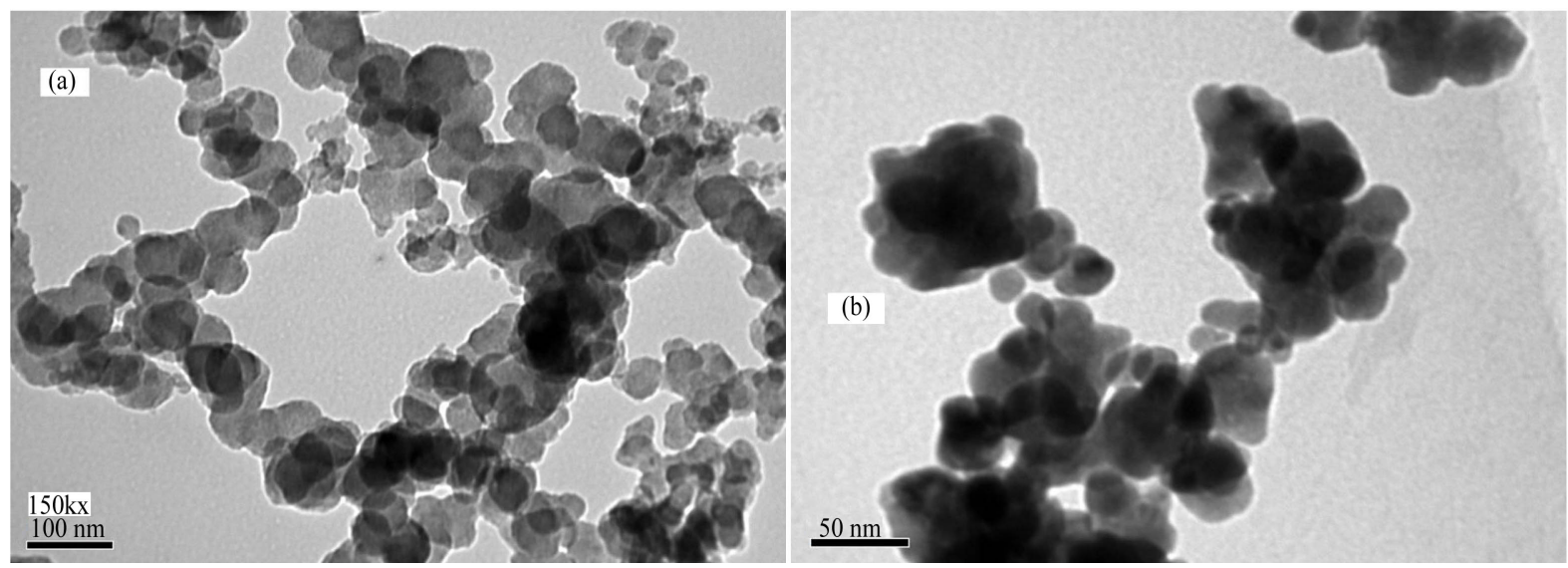

Figure 4. TEM images of monolithic samples $\mathrm{SPAE}_{1.2} \mathrm{Y}_{1.8}$ doped with 0.7 (a) and $1.3 \mathrm{~mol} \% \mathrm{Sm}_{2} \mathrm{O}_{3}$ (b), as sintered for three hours at $900^{\circ} \mathrm{C}$.

ions concentration and different concentrations of $\mathrm{Sm}^{3+}$ ions are correspond to $\mathrm{SiP}_{2} \mathrm{O}_{7}, \mathrm{Si}_{5} \mathrm{P}_{6} \mathrm{O}_{25}$ and $\mathrm{Si}_{3}\left(\mathrm{PO}_{4}\right)_{4}$, JCPDS [71-2073], [81-1593] and [49-0206], respectively. It is clearly seen that the intensity of the peaks increase by increasing the $\mathrm{Sm}^{3+}$ ions concentrations. Rare earth oxides and related compounds are in so small 


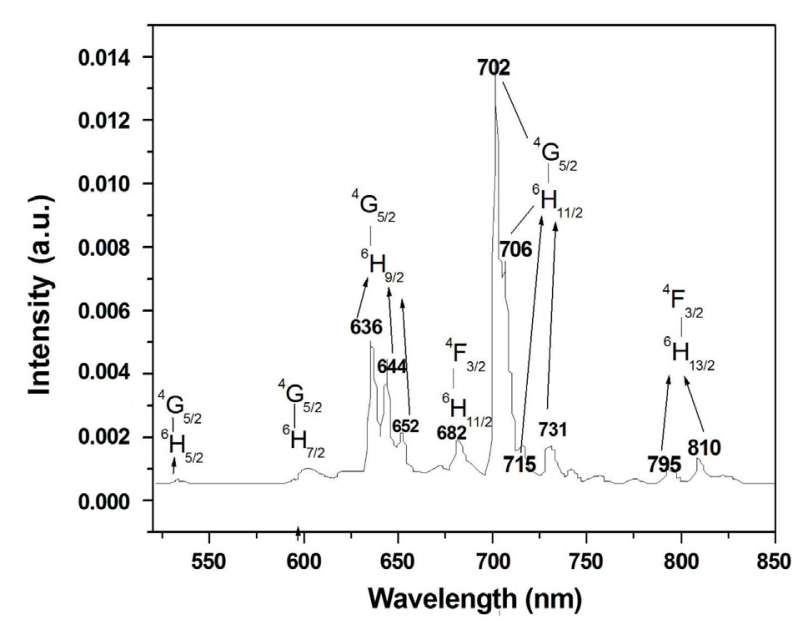

Figure 5. The photoluminescence (PL) emission spectra of thin film SPAE1.2Y1.8S0.7, sintered for three hours at $500^{\circ} \mathrm{C}$.

quantities that they might not appeared with their corresponding X-ray diffraction patterns. The general behavior observed from the values of the crystallite size and the intensity increasing of the peaks by increasing the $\mathrm{Sm}^{3+}$ ions from 0.7 up to $1.3 \mathrm{~mol} \%$ is its increase trend by doping with $1.3 \mathrm{~mol} \%$ of $\mathrm{Sm}^{3+}$ ions, this may be due to the co-doped with $\mathrm{Al}^{3+}$ ions, which enhance the solubility of samarium inside the host matrix.

Figure 3 shows the XRD pattern of the thin film SPAE $\mathrm{S}_{1.2} \mathrm{Y}_{1.8} \mathrm{~S}_{1.3}$ sintered at $900^{\circ} \mathrm{C}$ for three hours. Nearly the same phases obtained from XRD patterns of monolith samples are clearly appeared in thin film sample, but the peaks have lower intensity than monolith samples due to the low thickness of film.

The crystallite size of $\mathrm{SPAE}_{1.2} \mathrm{Y}_{1.8} \mathrm{~S}_{1.3}$ sintered at $900^{\circ} \mathrm{C}$ for three hours was of the order of $44 \mathrm{~nm}$ for monolith sample. By decreasing the $\mathrm{Sm}^{3+}$ ion concentrations the crystalline size was decreased [5] [11] [12]. It is also seems that the thin film $\mathrm{SPAE}_{1.2} \mathrm{Y}_{1.8} \mathrm{~S}_{1.3}$ sample sintered at $900^{\circ} \mathrm{C}$, gave smaller crystalline size than monolith sample giving the following value $31 \mathrm{~nm}$. The obtained XRD data are confirmed by using the Win-fit program.

The transmission electron microscopy TEM was used to confirm and complement the results obtained from XRD, as shown in Figure 4(a) and Figure 4(b) of monolith SPAE $\mathrm{S}_{1.2} \mathrm{Y}_{1.8} \mathrm{~S}_{0.07}$ (a) and SPAE $\mathrm{S}_{1.2} \mathrm{Y}_{1.8} \mathrm{~S}_{1.3}$ (b) both sintered at $900^{\circ} \mathrm{C}$. The patterns indicated the presence of the practically spherical with some agglomeration. The grain size was determined by averaging over the total number of grains in the TEM (Jeol1230) micrograph. Based on this method, the average crystallite size calculated from TEM was very close to the obtained from $\mathrm{XRD}$ for the same sample $\mathrm{SPAE}_{1.2} \mathrm{Y}_{1.8} \mathrm{~S}_{1.3}$ and was found to be equal to about $36 \mathrm{~nm}$.

Figure 5 shows the photoluminescence (PL) emission spectra under Argon laser excitation at wavelength $(488 \mathrm{~nm})$ of thin film SPAE ${ }_{1.2} \mathrm{Y}_{1.8} \mathrm{~S}_{0.7}$, sintered for three hours at $500^{\circ} \mathrm{C}$. It is expected here that all the energy levels of $\mathrm{Er}^{3+}: \mathrm{Yb}^{3+}$ system will be reconstructed when doped with $\mathrm{Sm}^{3+}$ ions in Alumina-Phospho-Silicates system. It is well known that the absorption cross-section of $\mathrm{Er}^{3+}$ and $\mathrm{Sm}^{3+}$ ions are small, for that $\mathrm{Yb}^{3+}$ ions was used as a sensitizer to increase the $\mathrm{Er}^{3+}$ and $\mathrm{Sm}^{3+}$ ions PL emission and offering good spectral overlap with $\mathrm{Er}^{3+}$ and $\mathrm{Sm}^{3+}$ transition, thus allowing efficient $\mathrm{Yb}^{3+}-\mathrm{Er}^{3+}-\mathrm{Sm}^{3+}$ energy transfer with subsequent $\mathrm{Er}^{3+}$ emission. It has

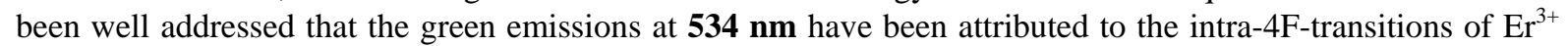
and $\mathrm{Sm}^{3+}$ ions and were assigned for both rare earth elements to the $\left({ }^{2} \mathrm{H}_{11 / 2}-{ }^{4} \mathrm{I}_{15 / 2}\right)$ and ${ }^{4} \mathbf{G}_{5 / 2}-{ }^{\mathbf{6}} \mathbf{H}_{5 / 2}$, respectively. The group red emission is attributed to another $4 \mathrm{~F}$-transition of $\mathrm{Er}^{3+}$ and $\mathrm{Sm}^{3+}$ ions assigned to $\left({ }^{4} \mathrm{~F}_{9 / 2}-{ }^{4} \mathrm{I}_{15 / 2}\right)$ for $\mathrm{Er}^{3+}$ ions. While it was assigned to ${ }^{4} \mathrm{G}_{5 / 2}-{ }^{6} \mathrm{H}_{7 / 2}$ at $604 \mathrm{~nm},{ }^{4} \mathrm{G}_{5 / 2}-{ }^{6} \mathrm{H}_{9 / 2}$ at wavelength 636, 644 and 652 nm, ${ }^{4} \mathbf{F}_{3 / 2}-{ }^{6} \mathbf{H}_{11 / 2}$ at wavelength $685 \mathrm{~nm},{ }^{4} G_{5 / 2}-{ }^{6} \mathbf{H}_{11 / 2}$, for 702 and $715 \mathrm{~nm}, 731$, and ${ }^{4} \mathbf{F}_{3 / 2}-{ }^{6} \mathbf{H}_{13 / 2}$ for 795 and 810

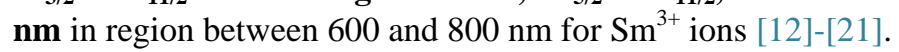

The red emission is much stronger than green emissions, which may be due to effect of doping the prepared samples with $\mathrm{Yb}^{3+}$ ions. The introduction of $\mathrm{Yb}^{3+}$ ions in silica-phosphate host brings about great changes for the photoluminescence properties of $\mathrm{Er}^{3+}$ and $\mathrm{Sm}^{3+}$ ions and a moderate green to red light can be seen in thin film sample under the same excitation. Where the multiplicity of RE sites in the host matrix is known to enhance the inhomogeneous broadening of the emission and absorption lines and a red shift was observed for the emission lines. 


\section{Conclusion}

Nano-composite Alumina-Phospho-Silicates doped with 3 different $\mathrm{RE}^{3+}$ erbium, ytterbium and samarium ions: $\left(\mathrm{SiO}_{2}: 11 \mathrm{P}_{2} \mathrm{O}_{5}: 3 \mathrm{Al}_{2} \mathrm{O}_{3}: 1.2 \mathrm{Er}: 1.8 \mathrm{Yb}:(1.3) \mathrm{Sm}\right)$, were successfully prepared by using a modified sol-gel technique, in two different forms monolith and thin film. The structure of the prepared samples was evaluated by using XRD, which revealed that the crystallite sizes decreased in thin film sample than monolith one from 44 to $31 \mathrm{~nm}$ by triply doped them with $\mathrm{Er}^{3+}, \mathrm{Yb}^{3+}$ and $\mathrm{Sm}^{3+}$ ions. It is well known that the absorption cross-section of $\mathrm{Er}^{3+}$ and $\mathrm{Sm}^{3+}$ ions is small, for that $\mathrm{Yb}^{3+}$ ions are used as a sensitizer to increase the $\mathrm{Er}^{3+}$ and $\mathrm{Sm}^{3+}$ ions PL emission and offering good spectral overlap with $\mathrm{Er}^{3+}$ and $\mathrm{Sm}^{3+}$ transition, thus allowing efficient $\mathrm{Yb}^{3+}-\mathrm{Er}^{3+}-\mathrm{Sm}^{3+}$ energy transfer with subsequent $\mathrm{Er}^{3+}$ emission.

\section{References}

[1] Tung, S.-P. and Hwang, B.-J. (2004) High Proton Conductive Glass Electrolyte Synthesized by an Accelerated Sol-Gel Process with Water/Vapor Management. Journal of Membrane Science, 241, 315-323.

http://dx.doi.org/10.1016/j.memsci.2004.06.003

[2] Massiot, Ph., Centeno, M.A., Carrizosa, I. and Odrio-zola, J.A. (2001) Thermal Evaluation of Sol-Gel-Obtained Phospho-Silicate Solids (Sipo). Journal of Non-Crystalline Solids, 292, 158-166. http://dx.doi.org/10.1016/S0022-3093(01)00854-7

[3] Battisha, I.K., Salem, M.A., Nahraw, A.M.S., Badr, Y. and Youssef, M.K.M. (2009) Erbium Activated Monolith SilicaPhosphate Glasses Planar Waveguide and Up-Conversion Mechanism. International Journal of Nano and Biomaterials, 2, 191-203.

[4] Badr, Y., Battisha, I.K., El Nahrawy, A.M.S. and Kamal, M. (2011) Physical Study of Thin Film and Monolithic NanoComposites [ $\mathrm{SiO}_{2}: 11 \mathrm{P}_{2} \mathrm{O}_{5}: 3 \mathrm{Al}_{2} \mathrm{O}_{3}:(1.2) \mathrm{Er}(1.2,1.8$ and 3)Yb] Prepared by Sol Gel Technique, Planar Waveguide and Co-operative Up-Conversion. New Journal of Glass and Ceramics, 1, 69-78. http://dx.doi.org/10.4236/njgc.2011.12012

[5] Kamal, M., Battisha, I.K., Salem, M.A. and El Nahrawy, A.M.S. (2011) Structural and Thermal Properties of Monolithic Silica-Phosphate $\left(\mathrm{SiO}_{2}-\mathrm{P}_{2} \mathrm{O}_{5}\right)$ Gel Glasses Prepared by Sol-Gel Technique. Journal of Sol-Gel Science and Technology, 58, 507-517. http://dx.doi.org/10.1007/s10971-011-2420-0

[6] Battisha, I.K. (2002) Structural And Optical Properties Of Monolithic Silica Gel Glasses Containing Nd ${ }^{3+}$ Using Two Different Precursors TEOS and TMOS Prepared by Sol-Gel. Indian Journal of Pure and Applied Physics, 40, 122-131.

[7] Badr, Y., Battisha, I.K., Salah, A. and Salem, M.A. (2008) Up-Conversion Luminescence Application in $\mathrm{Er}^{3+}$ :TiO 2 Thin Film Prepared by Dip Coating Sol-Gel Route. Indian Journal of Pure and Applied Physics, 46, 706-711.

[8] Battisha, I.K., El Beyally, A., Soliman, S.L. and El Nahrawi, A.S. (2007) Structural and Optical Studies of Activated Thin Film and Monolith Nano-Structure Silica Gel Doped with Different Rare Earth Elements, Prepared by Two Different Sol-Gel Techniques. Indian Journal of Pure and Applied Physics, 45, 441-453.

[9] Battisha, I.K. (2002) Physical Properties of Nano-Particle Silica Gel Doped with CdS Prepared by Sol-Gel Technique. Fizika A, 11, 61-72.

[10] Battisha, I.K. (2007) Visible Up-Conversion Photoluminescence from IR Diode-Pumped $\mathrm{SiO}_{2}-\mathrm{TiO}_{2}$ Nanocomposite Films Heavily Doped with $\mathrm{Er}^{3+}-\mathrm{Yb}^{3+}$ and $\mathrm{Nd}^{3+}-\mathrm{Yb}^{3+}$. Journal of Non-Crystalline Solids, 353, 1748-1754. http://dx.doi.org/10.1016/j.jnoncrysol.2007.01.043

[11] Rao, R.P. and Devine, D.J. (2000) RE-Activated Lanthanide Phosphate Phosphors for PDP Applications. Journal of Luminescence, 87-89, 1260-1263. http://dx.doi.org/10.1016/S0022-2313(99)00551-7

[12] Dhanaraj, J., Jagannathan, R., Kutty, T.R.N. and Lu, C.-H. (2001) Photoluminescence Characteristics of $\mathrm{Y}_{2} \mathrm{O}_{3}: \mathrm{Eu}^{3+}$ Nanophosphors Prepared Using Sol-Gel Thermolysis. The Journal of Physical Chemistry B, 105, 11098-11105. http://dx.doi.org/10.1021/jp0119330

[13] Ennen, H., Kaufmann, U., Pomrenke, G., Schneider, J., Windscheif, J. and Axmann, A. (1983) Rare Earth Activated Luminescence in InP, GaP and GaAs. Journal of Crystal Growth, 64, 165-168. http://dx.doi.org/10.1016/0022-0248(83)90264-6

[14] Zhu, Z.H., Sha, M.J. and Lei, M.K. (2008) Controllable Formation of $\mathrm{Er}^{3+}-\mathrm{Yb}^{3+}$ Codoped $\mathrm{Al}_{2} \mathrm{O}_{3}$ Films by the NonAqueous Sol-Gel Method. Thin Solid Films, 516, 5075-5078. http://dx.doi.org/10.1016/j.tsf.2008.02.016

[15] Li, C., Dong, B., Li, S. and Song, C. (2007) $\mathrm{Er}^{3+}-\mathrm{Yb}^{3+}$ Co-Doped Silicate Glass for Optical Temperature Sensor. Chemical Physics Letters, 443, 426-429. http://dx.doi.org/10.1016/j.cplett.2007.06.081

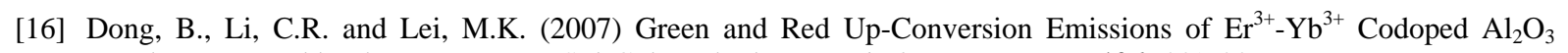
Powders Prepared by the Nonaqueous Sol-Gel Method. Journal of Luminescence, 126, 441-446. 
http://dx.doi.org/10.1016/j.jlumin.2006.08.091

[17] Timoshenko, V.Yu., Zhigunov, D.M., Kashkarov, P.K., Shalygina, O.A., Teterukov, S.A., Zhang, R.J., Zacharias, M., Fujii, M. and Hayashi, Sh. (2006) Photoluminescence Properties of Erbium-Doped Structures of Silicon Nanocrystals in Silicon Dioxide Matrix. Journal of Non-Crystalline Solids, 352, 1192-1195.

http://dx.doi.org/10.1016/j.jnoncrysol.2005.11.119

[18] Digonnet, M.J.F. and Snitzer, E. (1993) Chap. 5. In: Digonnet, M.J.F., Ed., Rare Earth Doped Fiber Lasers and Amplifiers, Marcel Dekker, New York.

[19] Bigot, L., Jurdyc, A.-M., Jacquier, B., Gasca, L. and Bayart, D. (2002) Resonant Fluorescence Line Narrowing Measurements in Erbium-Doped Glasses for Optical Amplifiers. Physical Review B, 66, Article ID: 214204. http://dx.doi.org/10.1103/PhysRevB.66.214204

[20] Yu, M., Lin, J., Zhou, Y.H., Pang, M.L., Han, X.M. and Wang, S.B. (2003) Luminescence Properties of $\mathrm{RP}_{1-\mathrm{x}} \mathrm{V}_{\mathrm{x}} \mathrm{O}_{4}$ : $\mathrm{A}$ $\left(\mathrm{R}=\mathrm{Y}, \mathrm{Gd}, \mathrm{La} ; \mathrm{A}=\mathrm{Sm}^{3+}, \mathrm{Er}^{3+} \mathrm{X}=0,0.5,1\right)$ Thin Films Prepared by Pechini Sol-Gel Process. Thin Solid Films, 444, 245253. http://dx.doi.org/10.1016/S0040-6090(03)01130-1

[21] Ennen, H., Kaufmann, U., Pomrenke, G., Schneider, J., Windscheif, J. and Axmann, A. (1983) Rare Earth Activated Luminescence in InP, GaP and GaAs. Journal of Crystal Growth, 64, 165-168. http://dx.doi.org/10.1016/0022-0248(83)90264-6 